\title{
HIGHLIGHT MISCONCEPTIONS IN PHYSICS: A T.I.M.E. PROJECT
}

\author{
Matteo Bozzi ${ }^{1}$, Patrizia Ghislandi², Kazuhiko Tsukagoshi ${ }^{3}$, Mami Matsukawa ${ }^{3}$, \\ Motoi Wada ${ }^{3}$, Naoto Nagaoka ${ }^{3}$, Alexey B. Pnev ${ }^{4}$, Andrey A. Zhirnov ${ }^{4}$, Gwenaëlle \\ Guillerme ${ }^{5}$, Maurizio Zani ${ }^{1}$ \\ ${ }^{1}$ Department of Physics, Politecnico di Milano (ITALY) \\ ${ }^{2}$ Department of Psychology and Cognitive Sciences, Università degli Studi di Trento (ITALY) \\ ${ }^{3}$ Graduate School of Science and Engineering, Doshisha University (JAPAN) \\ ${ }^{4}$ SEC "Photonics \& IR-technology", Bauman Moscow State Technical University (RUSSIAN \\ FEDERATION) \\ ${ }^{5}$ T.I.M.E. Association (FRANCE)
}

\begin{abstract}
Since the early 1970s it has been pointed out that many higher education students have a fairly large number of mistaken ideas on some Physics topics. Indeed, the term "misconceptions" was introduced for the first time in 1972. This theme is worthy of investigation in order to improve the students' outcomes in basic Physics courses and to tackle the issue of the growing number of dropouts.

Consisting of three main stages closely connected with each other, our research aims at identifying, comparing and overcoming the most significant and widespread misconceptions shown by first-year university students enrolled for engineering, in relation to their basic knowledge of Physics, with specific reference to Mechanics, Thermodynamics and Electromagnetism. It is being developed by Politecnico di Milano [ITA] along with Doshisha University [JAP] and Bauman Moscow State Technical University [RUS], which offer Physics and Engineering courses, as well as with Università degli Studi di Trento [ITA], which provides pedagogic support.

First of all, data about the above mentioned misconceptions were gathered by each technical institution through the use of an ad hoc test, which consisted of 12 multiple choice quizzes administered to about 750 students attending the 7 courses globally involved in the research. Hence, misconceptions related to the main macro-areas were further classified according to specific headings, i.e. kinematics, heat engine, electric field, among others.
\end{abstract}

Secondly, the misconceptions expressed by the students attending the different universities involved in the research were compared. They appear to be broadly widespread among the freshmen, with Electromagnetism being the macro-area where the students' results are the worst.

Throughout the third and final stage of our study, a trial video has been produced to enable students to overcome some significant misconceptions.

Keywords: Physics misconceptions, Higher Education, Open Educational Resources.

\section{INTRODUCTION}

The freshmen who attend a university basic Physics course do not start with a clean slate [1] but rather with their own personal view and interpretative schemas of many physical phenomena. Indeed, they attend the lectures taking with them the ideas and concepts which they have accrued from their previous learning and experience. Unfortunately, since the early 1970s it has been pointed out that a lot of these higher education students' ideas on some Physics topics are incorrect $[2,3,4]$. With relation to these erroneous viewpoints, the term "misconceptions" was introduced for the first time in $1972[5]$ in the context of a research focused on elementary school children.

Defined as ideas at variance with recognised views [6] or dissimilar from the ones generally acknowledged by scientists [7], misconceptions can be classified into the following categories [8]:

a) preconceived notions, which are widespread understandings embedded in daily experiences;

b) non-scientific believes, consisting in interpretative schemas learned from non-scientific sources;

c) conceptual misunderstandings, characterised by the fact that the students construct defective models by themselves without any external influence; 
d) vernacular misconceptions, related to the use of words whose general meaning is different from the meaning accepted in the world of science;

e) factual misconceptions, consisting in erroneous ideas and concepts often learnt during childhood and considered unchangeable.

Some misconceptions are persistent over the course of time $[9,10]$. Indeed, some research has highlighted that students continue to apply their own personal view and interpretative schemas when they deal with new situations and problems or perform outside school [11]. As a consequence, identifying potential freshmen's misconceptions on Physics at the beginning of their university learning path is fundamental in order to achieve an adequate level of knowledge and satisfactory outcomes in the Physics course final examination as well as to decrease the probability of failure and the possible dropouts. Furthermore, it might contribute to implement and increase the effectiveness of some teaching tools like MOOCs and preparatory Physics courses offered more and more frequently to students before they attend an academic programme [12,13] and aimed at bridging the gap between what they really know and what they should know.

It is worth emphasizing some original characteristics of our study. On the one hand, some new possible areas of Physics misconceptions are explored and compared with ones that can be found in the scientific literature. On the other hand, the three academic institutions which took part in our research show significant environmental, social, economic, educational and cultural differences. Comparing the misconceptions expressed by freshmen belonging to such different backgrounds could lead to a deeper comprehension of the origins of those misconceptions. Consequently, more effective and clever strategies to overcome them might be identified.

\section{METHODOLOGY}

Our research aims at identifying, comparing and overcoming some significant and widespread misconceptions shown by first-year university students enrolled for engineering, in relation to their basic knowledge of Physics, with specific reference to Mechanics, Thermodynamics and Electromagnetism. It has been developed by Politecnico di Milano [ITA] along with Bauman Moscow State Technical University [RUS] and Doshisha University [JAP], which offer Physics and engineering courses, as well as with another Italian institution, Università degli Studi di Trento, which provides pedagogic support.

Firstly, the three universities selected the basic Physics courses involved in the research and identified the notable data which had to be gathered; table 1 synthesises some data collected.

Table 1. Data about the basic Physics courses involved in the research

\begin{tabular}{|l|l|l|c|c|c|}
\hline University & \multicolumn{1}{|c|}{ Course } & \multicolumn{1}{|c|}{ Study course } & $\begin{array}{c}\text { Student } \\
\text { year }\end{array}$ & $\begin{array}{c}\text { Course } \\
\text { semester }\end{array}$ & $\begin{array}{c}\text { Possible } \\
\text { students } \\
\text { involved }\end{array}$ \\
\hline Politecnico & $\begin{array}{l}\text { Experimental Physics } \\
\text { A+B }\end{array}$ & Materials Engineering & 1 & 1 & 200 \\
\hline Politecnico & Experimental Physics A+B & Materials Engineering & 1 & 1 & 200 \\
\hline Politecnico & Experimental Physics A+B & Materials Engineering & 1 & 1 & 200 \\
\hline Politecnico & Experimental Physics II & Engineering Physics & 2 & 1 & 200 \\
\hline Politecnico & Experimental Physics A+B & Mathematical Engineering & 2 & 1 & 200 \\
\hline Bauman & Physics II & Optics & 1 & 1 & 100 \\
\hline Bauman & Physics II & Special Machines & 1 & 1 & 100 \\
\hline Bauman & Physics II & automatization & 1 & 1 & 50 \\
\hline Bauman & Physics II & $\begin{array}{l}\text { Business and } \\
\text { Management }\end{array}$ & 1 & 1 & 30 \\
\hline Doshisha & Fundamental Physics II & Electronics & 1 & 2 & 85 \\
\hline
\end{tabular}

1 In Politecnico di Milano the course title use some alphabetic letters to identify the content' topics. For instance, in this case $A+B$ means that course regards Mechanics and Electromagnetism. 
In order to investigate the possible students' misconceptions, several strategies were adopted in the past by the researchers: interviews [14], open-ended tests [15] and multiple-choice tests [16] are an example. Taking into account the massive number of students potentially involved in our study and the geographical remoteness of the academic institutions involved, a multiple-choice test appeared to be an adequate and neat choice to carry out our research. This test, identical for all the universities which took part in the study, was designed by the Experimental teaching lab. ST2 ${ }^{2}$ of Politecnico di Milano in cooperation with Università degli Studi Trento, which addressed respectively the Physics topics and the educational aptness of the test itself. The questions of this test have been built on the basis of the following elements:

a) the most common errors made by freshmen during their final exam, which generally consisted of three Physics problems and one open response question on a theoretical issue;

b) the questions more frequently asked by students when they attend their lessons or drills;

c) the literature on misconceptions in Physics.

A specific heading, related to one of the macro-areas previously identified, has been allocated to each question of the trial. Table 2 summarises the classification of quizzes and misconceptions.

Table 2. Quizzes classification based on misconception areas, specific headings and macro-areas of Physics

\begin{tabular}{|c|c|c|c|}
\hline Quiz & Misconception area & Specific heading & Macro-area \\
\hline 1 & Displacement and distance travelled & Kinematics & Mechanics \\
\hline 2 & Static friction & Force & " \\
\hline 3 & Impulse, momentum law & Linear momentum & “ \\
\hline 4 & Conservation of energy, linear and angular momentum & Gravitation & “ \\
\hline 5 & Phase transition and heat exchanged & $\begin{array}{l}\text { Thermodynamics } \\
\text { processes }\end{array}$ & Thermodynamics \\
\hline 6 & Relation between heat and energy of a Thermodynamics system & Heat & “ \\
\hline 7 & Quasi-static and no quasi-static adiabatic process & $\begin{array}{l}\text { Thermodynamics } \\
\text { processes }\end{array}$ & “ \\
\hline 8 & Efficiency of an heat engine and comparison with Carnot engine & Heat engine & “ \\
\hline 9 & Source of an electric field & Electric field & Electromagnetism \\
\hline 10 & Electrical induction & Conductors & “ \\
\hline 11 & Electric field in the presence of a dielectric & Dielectrics & “ \\
\hline 12 & Equilibrium of a current loop lying in a magnetic field & Magnetostatics & “ \\
\hline
\end{tabular}

The test was written in Italian and then translated into English; both Bauman Moscow State Technical University and Doshisha University converted it respectively into Russian and Japanese, therefore it was submitted to each student in their own mother tongue. Administered at the beginning of each course, between September 2018 and November 2018, the test consisted of 12 multiple choice quizzes, 4 based on Mechanics topics, 4 on Thermodynamics subjects and 4 on Electromagnetism themes. Only one answer was correct, hence the possible misconceptions related to that topic were generally explored through the other three incorrect alternatives.

The time allotted to each quiz, 90 seconds, and the order of the questions were previously established, consequently the students could not manage their time, nor the order to answer the quizzes. The test was supposed to be administered to all the students through the online portal Socrative and their own electronic devices, like smartphones, tablets and laptops alike. Nevertheless, Bauman Moscow State Technical University had to resort to a traditional paper administration owing to technical problems. During the test a tutor complemented the teacher to control the entire procedure: however, no interaction with the students was allowed nor suggestions to them were provided with relation to the correct solutions.

\footnotetext{
2 Playing on the graphic representation of carbon hybridization state (sp2) and its double bond (=), the laboratory aims to study and experiment new teaching methods and technologies in Physics courses in order to enhance the interactions between the Students and the Teachers (http://www.st2.fisi.polimi.it).
} 


\section{RESULTS}

We preliminarily analysed the overall results of the experimental treatment, comparing and contrasting the freshmen's groups of the three universities engaged in the activity; table 3 shows the percentage of incorrect answers related to each quiz and every academic institution.

With no distinction among Politecnico di Milano and Doshisha, the lowest rate of wrong answers related to a single quiz is just below $50 \%$ as well as the highest one is more than $85 \%$. Furthermore, if the level of difficulty of a single question is classified by the percentage of incorrect answers given by the students (easy question if the wrong answers are less than $30 \%$, difficult if they are more than $65 \%$, regular otherwise) [17], one could argue that there are no easy questions for Politecnico di Milano's and Doshisha's students in the test and these quizzes are difficult 8 times out of 12. Hence, misconceptions investigated appear to be broadly widespread among the freshmen.

On the other hand, the Bauman students' findings highlight that only 5 quizzes of the test can be classified as difficult, and two (question 1 and 5) are substantially easy. Nonetheless, misconceptions are still largely disseminated among the Russian students.

Finally, the freshmen of all universities involved in the study show their best performance in a quiz based on Thermodynamics (question 5), whereas the worst outcome is related to a question (quiz 10) focused on electrical induction.

Table 3. Percentage of incorrect answers related to each quiz and university involved in the research

\begin{tabular}{|c|c|c|c|c|c|c|c|c|c|c|c|c|c|}
\hline \multirow[t]{3}{*}{ University } & \multirow[t]{3}{*}{ Students number } & \multicolumn{12}{|c|}{ Percentage of incorrect answers related to each quiz } \\
\hline & & \multicolumn{4}{|c|}{ Mechanics } & \multicolumn{4}{|c|}{ Thermodynamics } & \multicolumn{4}{|c|}{ Electromagnetism } \\
\hline & & 1 & 2 & 3 & 4 & 5 & 6 & 7 & 8 & 9 & 10 & 11 & 12 \\
\hline Politecnico & 478 & 85.4 & 75.9 & 69.9 & 87.0 & 49.2 & 50.6 & 84.1 & 49.0 & 64.0 & 92.1 & 88.5 & 89.5 \\
\hline Bauman & 183 & 30.1 & 67.8 & 59.0 & 80.3 & 23.5 & 63.4 & 83.1 & 63.4 & 56.3 & 85.8 & 52.5 & 70.5 \\
\hline Doshisha & 89 & 58.4 & 77.5 & 64.0 & 78.7 & 48.3 & 66.3 & 73.0 & 59.6 & 73.3 & 85.4 & 76.4 & 82.0 \\
\hline
\end{tabular}

By grouping the different quizzes into some macro-areas, as shown in table 4, it might be pointed out that the students' misconceptions tend to increase if Thermodynamics, Mechanics and Electromagnetism are respectively considered. Although the international academic institutions which took part in the research are characterised by significant environmental, social, economic, educational and cultural differences, it is worth emphasizing that all the universities show the lowest rate of incorrect answers with relation to Thermodynamics, whereas the highest percentage of wrong ones is related to Electromagnetism. However, unlike Politecnico di Milano and Doshisha, the results of Bauman students in Mechanics are essentially equivalent to their outcomes in Thermodynamics. Nevertheless, the rate of wrong answers related to each quiz and macro-area appears sometimes to be rather dissimilar among the three universities, i.e. quizzes 1, 8, 11 as shown in Table 3 and Mechanics and Electromagnetism in Table 4.

Table 4. Percentage of incorrect answers related to each macro-area and every one university involved in the research

\begin{tabular}{|l|c|c|c|c|}
\hline University & Students number & \multicolumn{3}{|c|}{ Percentage of incorrect answers related to each macro-area } \\
\hline & & Mechanics & Thermodynamics & Electromagnetism \\
\hline Politecnico & 478 & 79.6 & 58.2 & 83.5 \\
\hline Bauman & 183 & 59.3 & 58.3 & 66.3 \\
\hline Doshisha & 89 & 69.7 & 61.8 & 79.2 \\
\hline
\end{tabular}

\section{CONCLUSIONS}

Nowadays, the awareness that students who attend a university basic Physics course have some mistaken ideas and erroneous points of view on many Physics phenomena is widely accepted. Investigating traditional along with original misconceptions, our study corroborates this consciousness. 
Moreover, it points out how much they are largely deep-rooted in the freshmen, independently of their nationality, previous learning path and cultural tradition.

A novelty introduced by our research is the simultaneous investigation of misconceptions related to different Physics macro-areas, Mechanics, Thermodynamics and Electromagnetism alike. It has been emphasized that students have many misconceptions in all these branches of Physics; nonetheless their spread decreases if Electromagnetism, Mechanics and Thermodynamics are respectively considered.

Another original characteristic of our study is the comparison among the misconceptions of freshmen who attend three universities which show so significant environmental, social, economic, educational and cultural differences. The large discrepancy in the percentages of incorrect answers related to the same quiz (i.e. question $1,8,11$ ) among the different academic institutions could allow higher education stakeholders to get a deeper understanding of the origins of these misconceptions, in order to plan and implement some educational tools and strategies which might enable teachers to overcome them: the analysis of the data can pave the way for further investigation into the origins of the most noteworthy and widespread misconceptions and open up a new step.

Finally, taking into account that the students' findings in question 2 are substantially homogeneous in all the universities involved in our research - misconceptions on static friction are equally and broadly widespread -, the misconception area related to that answer has been selected as the topic of a Physics educational video which aims at helping freshmen to overcome these misconceptions on static friction. Indeed, it should serve as a first model for a series of further Physics educational videos and in an Open Educational Resources philosophy (OER) has been uploaded on Lab. ST2 YouTube channel ${ }^{3}$.

\section{ACKNOWLEDGEMENTS}

Our project is supported and financed by T.I.M.E. (Top Industrial Managers for Europe) , $^{4}$ an association of Technical Universities and Engineering Schools whose main purpose is to facilitate the exchange of students for Double Master Degrees in Engineering. The 54 members (most of them from European countries, but also from Australia, Brazil, China, Japan, Russia and Turkey) have a strong international dimension in their research, teaching and industrial relations and all are committed to international cooperation, exchange and recognition of studies abroad.

\section{REFERENCES}

[1] J. Piaget, B. Inhelder, "Le développement des quantités Physiques chez l'enfant: conservation et atomisme (3e éd)". Neuchatel-Paris: Delachaux \& Niestlé, 1968.

[2] J. Warren, "Circular motion", Physics Education, vol. 6, pp.74-77, 1971.

[3] U. M. O. Ivowi, "Misconceptions in physics amongst Nigerian secondary school students", Physics Education, vol. 19, pp.279-285, 1984.

[4] D. N. Utami, H. R. T. Wulandari, "The use of astronomy questions as an instrument to detect student's misconceptions regarding physics concepts at high school level by using CRI (Certainty of Response Index) as identification methods", Journal of Physics: Conference Series, vol. 771, 012027, 2016.

[5] R. L. Doran, "Misconceptions of Selected Science Concepts", Journal of Research in Science Teaching, vol. 9, pp. 127-137, 1972.

[6] K. M. Fisher, in H. Helm \& J. D. Novak (Chairs), Proceedings of the International Seminar on misconceptions in Science and Mathematics. Ithaca, NY: Cornell University, pp. 150-152, 1983.

[7] A. L. Odom, L. H. Barrow, "Development and application of a two-tier diagnostic test measuring college biology students' understanding of diffusion and osmosis after a course of instruction", Journal of Research in Science Teaching, vol. 32, pp. 45-61, 1995.

\footnotetext{
${ }^{3} \mathrm{https}: / /$ www.youtube.com/channel/UCWPywJuHizBrRStM6u_VY5A

${ }^{4}$ http://www.time-association.org
} 
[8] Committee on Undergraduate Science Education, "Misconceptions as Barriers to Understanding Science" in Science Teaching Reconsidered: A Handbook, pp. 27-32, Washington, D. C.: National Academies Press, 1997.

[9] A. Brown, S. David, J. Clement, "Misconceptions concerning Newton's law of action reaction", Proceedings of the Second International Seminar Misconceptions and Educational Strategies in Science and Mathematics, Ithaca, NY: Cornell University, vol. 3, pp. 39-53, 1987.

[10] D. Hammer, "The nature of naïve explanations of natural selection", International Journal of Science Education, vol. 20, pp. 1231-1250, 1989.

[11] R. T. White, "Implications of recent research on learning for curriculum and assessment", Journal of Curriculum Studies, vol. 24, no. 2, pp. 153-164, 1992.

[12] M. Zani, M. Bozzi, "La fisica tra la scuola secondaria e l'università. Riflessioni e orientamenti", Nuova Secondaria, vol. XXXVI, no 1, pp. 84-88, 2018.

[13] J. Raffaghelli, P. Ghislandi, M. Bozzi, M. Zani et al., "Integrating MOOCs in physics preliminary undergraduate education: beyond large size lectures", Educational Media International, vol. 55, no. 4, pp. 301-316, 2018.

[14] J. Park, S. Han, 'Using deductive reasoning to promote change of students' conceptions about force and motion", International Journal of Science Education, vol. 24, no. 6, pp. 593-609, 2010

[15] P. Colin, F. Chauvet, L. Viennot, "Reading images in optics: students' difficulties and teachers' views", International Journal of Science Education, vol. 24, no. 3, pp. 313-332, 2002

[16] T. Martín-Blas, L. Seidel, A. Serrano-Fernández, "Enhancing Force Concept Inventory diagnostics to identify dominant misconceptions in first-year engineering physics", European Journal of Engineering Education, vol. 35, 6, pp. 597-606, 2010.

[17] M. Bozzi, J. Raffaghelli, M. Zani, "Peer learning for large size Physics lectures in higher education: yes, we can", Proceedings of iCERi2018, pp. 8739-8747, Seville, Spain: IATED, 2018. 